\title{
Effects of carnitine and some related compounds on the motility of rat spermatozoa from the caput epididymidis
}

\author{
B. T. Hinton, D. E. Brooks*, H. M. Dott $\dagger$ and B. P. Setchell \\ Department of Physiology and $\dagger$ Animal Research Station, A.R.C. Institute of Animal \\ Physiology, Babraham, Cambridge CB2 4AT, U.K.
}

\begin{abstract}
Summary. Spermatozoa were collected from the rat caput epididymidis by micropuncture and their motility assessed after dilution in physiological saline containing carnitine or related compounds. $L(+)$-Carnitine caused, 2 min after dilution, a transient stimulation of the motility of spermatozoa with low initial motility. No stimulatory effects were seen on spermatozoa which had high initial motility. The D-isomer inhibited the motility of spermatozoa with high initial motility after $2 \mathrm{~min}$ and all compounds tested appeared to inhibit, at $20 \mathrm{~min}$ after dilution, the motility of spermatozoa with high initial motility. Acetyl-L-carnitine and acetylD-carnitine stimulated the motility of spermatozoa with low initial motility. This study suggests that carnitine may be important in the development by spermatozoa of the potential for motility and also to maintain mature spermatozoa in a quiescent state.
\end{abstract}

\section{Introduction}

High concentrations of carnitine are found in the rat epididymis (Marquis \& Fritz, 1965: Pearson \& Tubbs, 1967); concentrations of the order of 50 to $60 \mathrm{~mm}$ have been measured in the luminal fluid of the cauda epididymidis and ductus deferens (Brooks, Hamilton \& Mallek, 1974; Hinton, Snoswell \& Setchell, 1979b). Measurements of the concentration of carnitine in the luminal fluid along the rat epididymis indicate an abrupt increase in concentration in the caput epididymidis (Hinton et al., 1979b). This occurs at the point where the epididymis actively accumulates radioactive carnitine from the bloodstream (Brooks et al., 1973; Bøhmer \& Johansen, 1978) and transports it into the luminal fluid (Hinton \& Setchell, 1979) and where the spermatozoa acquire the potential for motility (Hinton, Dott \& Setchell, 1979a). This suggests that carnitine may influence the motility of immature spermatozoa. Although carnitine and acetylcarnitine have been shown to affect motility and respiration of mature spermatozoa from other species (Casillas, 1972; Hamilton \& Olsen, 1976; Tanphaichitr, 1977; Johansen \& Bøhmer, 1978) there have been no studies on the effects of carnitine on the motility of immature spermatozoa. We have therefore studied the effects of carnitine and related compounds on the motility of rat spermatozoa collected by micropuncture from the caput epididymidis just before and after the point where spermatozoa first develop the potential for motility.

\footnotetext{
* Present address: Department of Physiology, Waite Agricultura! Research Institute. The University of Adelaide. Glen Osmond, South Australia 5064, Australia.
} 


\section{Materials and Methods}

\section{Chemicals}

L-Carnitine hydrochloride was a gift from Otsuka Pharmaceutical Co., Japan, and D-carnitine hydrochloride, acetyl-L-carnitine hydrochloride, acetyl-D-carnitine hydrochloride were gifts from Dr P. K. Tubbs, University of Cambridge, U.K. Acetylcholine chloride, choline chloride (Sigma Co., London, U.K.) and D(+)-glucose (May \& Baker, Dagenham, U.K.) were used as obtained from the manufacturers.

\section{Solutions}

Stock solutions of L-carnitine hydrochloride, D-carnitine hydrochloride, choline chloride, acetyl-L-carnitine hydrochloride, acetyl-D-carnitine hydrochloride and acetylcholine chloride were neutralized to $\mathrm{pH} 7 \cdot 2-7.4$ with potassium bicarbonate and diluted to make isosmotic solutions (300-320 mosmol/kg water). Each solution was then mixed in the appropriate proportion with phosphate-buffered saline, $\mathrm{pH} 7 \cdot 2-7.4$ (PBS; Oxoid, U.K.) in order to achieve the desired final concentration and to maintain a constant osmolarity.

\section{Animals}

Adult male Porton-Wistar rats weighing 350-450 g were obtained from the Institute colony where they were housed under $14 \mathrm{~h}$ daylight with free access to food (Oxoid breeding diet) and water.

\section{Micropuncture}

The rats were prepared for micropuncture as previously described (Hinton et al., 1979a, b). Micropuncture samples, 70-100 $\mathrm{nl}$, were collected from the proximal and distal caput epididymidis (between Sites 2 and 3 respectively, see Hinton et al., 1979a) and immersed under water-saturated liquid paraffin oil on a recently cleaned cavity slide. Approximately $10 \mathrm{nl}$ samples were taken from the larger sample, mixed with $2.5 \mu$ PBS containing the various test solutions under water-saturated liquid paraffin oil, and incubated at $30^{\circ} \mathrm{C}$ for 20 or $30 \mathrm{~min}$ after dilution. A total of 59 samples were taken for measurement, at least 2 or 3 samples from each region in the caput epididymidis from 37 rats.

\section{Sperm motility measurement}

The sperm motility was assessed in Area-Change Frequency Units (ACF value) using a Quantimet Image Analyser (Cambridge Instrument Co., Royston, U.K.) (Dott \& Foster, 1979; Hinton et al., 1979a) after $2 \mathrm{~min}$ and again after $20 \mathrm{~min}$ on the slide or, in some experiments, after 2, 8, 14, 20 and $30 \mathrm{~min}$. Samples were classified as having low initial motility if the ACF value at 2 min after dilution in PBS was $<15$ and as having a high initial motility if the ACF value was $>22$. In the course of the experiments only one sample had an ACF value between these values and this was omitted from the analysis of results.

\section{Analysis of results}

The results were analysed by a paired $t$ test using (a) the control and treatment at the same time and (b) $2 \mathrm{~min}$ and $20 \mathrm{~min}$ in the same treatment except that the comparisons of the data obtained after 20 min exposure to various concentrations of carnitine were made by unpaired $t$ tests after $\log$ transformation to normalize the distribution. 


\section{Results}

As far as could be determined by observation under the dissecting microscope, the spermatozoa contained in the micropuncture samples from the caput epididymidis were completely immotile until diluted with PBS, as reported by Turner \& Howards (1978) and Hinton et al. (1979a).

To check on the consistency of the method for subsampling from a single micropuncture sample, 9 subsamples from a single high motility sample were diluted with PBS. The mean ACF at $2 \mathrm{~min}$ was $57 \pm 3$ (coefficient of variation of $16 \%$ ). The procedure for subsampling therefore appeared to produce a consistent result and comparisons were possible between treatments and control within each run.

When spermatozoa of the low initial motility group (see 'Methods') were diluted into PBS containing L-carnitine, a stimulation of motility was observed at $2 \mathrm{~min}$. The degree of stimulation of motility was dose-dependent and apparently maximal at about $30 \mathrm{~mm}$ (Table 1). However, the results were variable, as indicated by the relatively large standard errors, and only differences of large magnitude were statistically significant. Subsequently, the pattern was reversed in that the high concentrations of carnitine which stimulated motility at $2 \mathrm{~min}$ became inhibitory at $20 \mathrm{~min}$. The transient nature of the stimulation of motility by $30 \mathrm{~mm}$-carnitine is more apparent in the time course plotted in Text-fig. 1 and contrasts with that observed in the PBS control and at lower concentrations of carnitine.

Table 1. Mean \pm s.e.m. motility (measured in Area Change Frequency (ACF) units) of spermatozoa from the caput epididymidis of the rat in phosphate-buffered saline with carnitine

\begin{tabular}{|c|c|c|c|c|c|c|}
\hline \multirow{3}{*}{$\begin{array}{c}\text { L-Carnitine } \\
\text { (mM) }\end{array}$} & \multicolumn{3}{|c|}{ Low initial motility } & \multicolumn{3}{|c|}{ High initial motility } \\
\hline & \multirow{2}{*}{$\begin{array}{c}\text { No. of } \\
\text { samples }\end{array}$} & \multicolumn{2}{|c|}{ Motility at: } & \multirow{2}{*}{$\begin{array}{l}\text { No. of } \\
\text { samples }\end{array}$} & \multicolumn{2}{|c|}{ Motility at: } \\
\hline & & $2 \min$ & $20 \min$ & & $2 \mathrm{~min}$ & $20 \mathrm{~min}$ \\
\hline 0 & 15 & $5 \pm 1$ & $12 \pm 3^{* *}$ & 5 & $26 \pm 3$ & $35 \pm 9$ \\
\hline 3 & 9 & $8 \pm 3$ & $11 \pm 4$ & 4 & $20 \pm 5$ & $32 \pm 10$ \\
\hline 6 & 4 & $21 \pm 8$ & $20 \pm 8$ & 1 & $\overline{41}$ & $\overline{43}$ \\
\hline 9 & 9 & $24 \pm 69$ & $12 \pm 4$ & 4 & $34 \pm 17$ & $19 \pm 5^{*}$ \\
\hline 30 & 11 & $35 \pm 8 \pi$ & $4 \pm 2^{* * *} \ddagger$ & 4 & $46 \pm 10$ & $6 \pm 3^{*} 8$ \\
\hline 60 & 7 & $32 \pm 9+$ & $2 \pm 1 * * \S$ & 3 & $46 \pm 6$ & $22 \pm 15$ \\
\hline
\end{tabular}

Values were compared with those at $2 \mathrm{~min}$ in the same concentration of carnitine $\left({ }^{*} P<0.05 ;{ }^{* *} P<0.02\right.$; ${ }^{* * *} P<0.01$ : paired $t$ tests) and with those in 0 mM-carnitine at the same time $(\dagger P<0.05 ; 9 P<0.01$ : paired $t$ tests; $\S P<0.02 ; \ddagger P<0.01$ : unpaired $t$ tests).

Spermatozoa which exhibited high motility in PBS were unaffected by L-carnitine at 2 min, but at 20 min motility was significantly reduced in the presence of the higher concentrations of $\mathrm{L}$-carnitine. This inhibition was not significant at $60 \mathrm{~mm}$-carnitine due to one high reading which, in the light of the other results, would appear to have been atypical.

To determine whether the influence of L-carnitine was specific, its effects were compared with those of D-carnitine, choline and their acetyl derivatives (Table 2). In samples with low initial motility, neither D-carnitine nor choline influenced motility at 2 or $20 \mathrm{~min}$. On the other hand, both acetyl-L-carnitine and acetyl-D-carnitine, but not acetylcholine, stimulated motility at 2 min. In samples with high initial motility, D-carnitine was the only compound which reduced motility at $2 \mathrm{~min}$, but at 20 min motility was reduced by most of the treatments.

Since the PBS contained no oxidizable substrate, it was possible that the decline in motility observed after the initial stimulation by carnitine had resulted from exhaustion of endogenous substrates. This was tested by including glucose as an exogenous substrate in the PBS. However, glucose reduced rather than sustained sperm motility in both the presence and absence of L-carnitine (Table 2). 


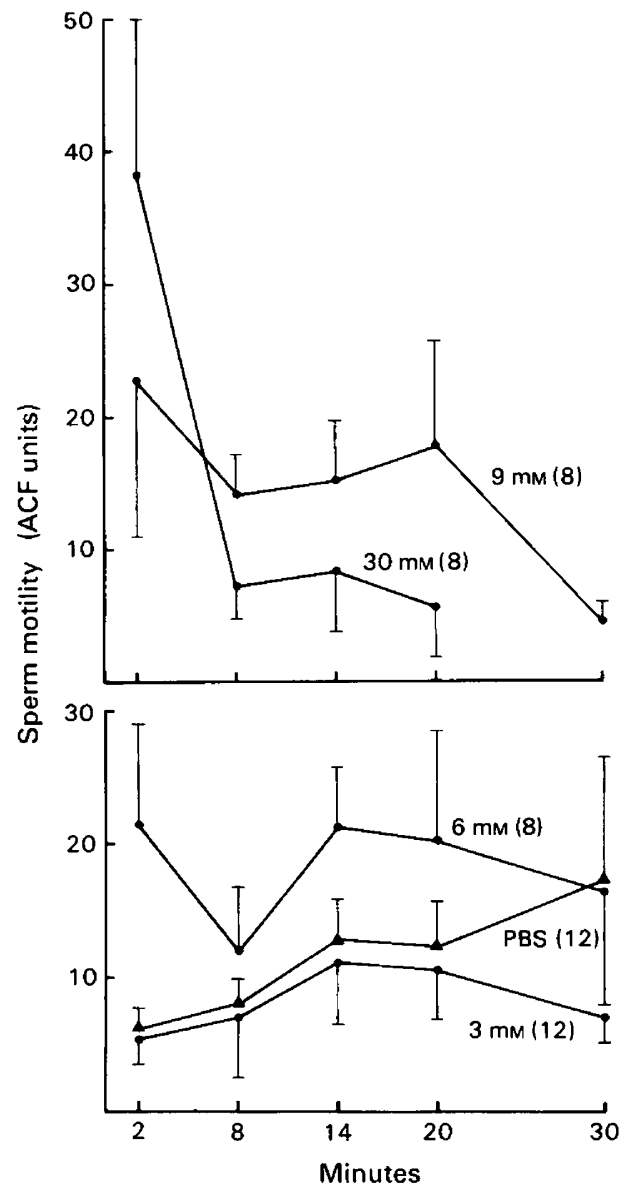

Text-fig. 1. Effects of different concentrations of L-carnitine ( $)$ and phosphate-buffered saline $(\Delta)$ on the motility of rat epididymal spermatozoa of low initial motility. Values are mean \pm s.e.m. for the no. of observations indicated in parentheses.

Table 2. Mean \pm s.e.m. motility (ACF units) of spermatozoa from the caput epididymidis of the rat in phosphate-buffered saline (PBS) with various additions

\begin{tabular}{|c|c|c|c|c|c|c|}
\hline \multirow[b]{3}{*}{ Addition } & \multicolumn{3}{|c|}{ Low initial motility } & \multicolumn{3}{|c|}{ High initial motility } \\
\hline & \multirow{2}{*}{$\begin{array}{l}\text { No. of } \\
\text { samples }\end{array}$} & \multicolumn{2}{|c|}{ Motility at: } & \multirow{2}{*}{$\begin{array}{l}\text { No. of } \\
\text { samples }\end{array}$} & \multicolumn{2}{|c|}{ Motility at: } \\
\hline & & $2 \min$ & $20 \mathrm{~min}$ & & $2 \mathrm{~min}$ & $20 \mathrm{~min}$ \\
\hline PBS & 27 & $5 \pm 1$ & $9 \pm 2^{*}$ & 17 & $40 \pm 4$ & $34 \pm 5$ \\
\hline L-Carnitine (30 mM) & 20 & $28 \pm 6 \ddagger$ & $8 \pm 3^{* * * *}$ & 8 & $32 \pm 9$ & $9 \pm 4^{*} \ddagger$ \\
\hline D-Carnitine (30 mM) & 16 & $7 \pm 3$ & $3 \pm 2 \dagger$ & 13 & $25 \pm 6 \ddagger$ & $14 \pm 4 \ddagger$ \\
\hline Choline (30 mm) & 10 & $12^{\prime} \pm 4$ & $10 \pm 5$ & 8 & $44 \pm 7$ & $17 \pm 6^{* *} \S$ \\
\hline Acetyl-L-carnitine $(30 \mathrm{~mm})$ & 14 & $22 \pm 5 \ddagger$ & $8 \pm 4^{* * * *}$ & 9 & $31 \pm 8$ & $13 \pm 6^{*}$ \\
\hline Acetyl-D-carnitine $(30 \mathrm{~mm})$ & 14 & $22 \pm 6 t$ & $10 \pm 4$ & 19 & $36 \pm 6$ & $14 \pm 7^{*}$ \\
\hline Acetyl-choline $(30 \mathrm{~mm})$ & 9 & $10 \pm 5$ & $<1^{*}$ & 7 & $32 \pm 9$ & $7 \pm 6^{* *}+$ \\
\hline Glucose (5 mM) & 9 & $10 \pm 5$ & $2 \pm 1$ & 7 & $27 \pm 8$ & $10 \pm 4 \dagger$ \\
\hline $\begin{array}{l}\text { L-Carnitine }(30 \mathrm{~mm})+ \\
\text { glucose }(5 \mathrm{~mm})\end{array}$ & 14 & $19 \pm 5 \S$ & $5 \pm 2^{* * *}$ & 9 & $33 \pm 8$ & $<1^{* * * \neq}$ \\
\hline
\end{tabular}

Values were compared with those at $2 \mathrm{~min}$ in the same concentration of carnitine $\left({ }^{*} P<0.05 ;{ }^{* *} P<0.02\right.$; ${ }^{* * *} P<0.01$ : paired $t$ tests) and with those in 0 mM-carnitine at the same time $(\dagger P<0.05 ; \S P<0.02 ; \ddagger P<0.01$ : paired $t$ tests). 


\section{Discussion}

In this study we have confirmed previous results (Hinton et al., 1979a) that within a short region of the rat caput epididymidis, spermatozoa acquire the potential for motility when diluted into a physiological solution. Since we could obtain samples only from tubules at the surface of the epididymis and without knowledge of the exact course of the tubules within the interior of the organ, we could not determine precisely what length of tubule was involved in the development of potential for motility. However, an analysis of carnitine in similar micropuncture samples (Hinton et al., 1979b) suggests that this region coincides with the region where the epididymidis first begins to accumulate carnitine. In the present study we obtained spermatozoa of low or high initial motility and we suspect that this difference in initial motility may reflect whether or not the spermatozoa had already come into contact with carnitine in the epididymal lumen. The small size of the samples obtained made it impossible to check this suggestion.

The samples obtained by micropuncture were also too small to provide material for metabolic studies and we have therefore been unable to establish the mechanism by which carnitine stimulates spermatozoa of low initial motility. However, we have established that stimulation of spermatozoa of low initial motility was specific to the naturally occurring L-isomer whereas the $\mathbf{D}$-isomer inhibited spermatozoa of high initial motility. We have also demonstrated that the transient character of the stimulation caused by $L$-carnitine was not due to a limitation of energy substrate since the addition of glucose to the medium did not help to sustain motility but actually reduced it. We therefore conclude that the reduced motility observed at $20 \mathrm{~min}$ in the presence of L-carnitine for spermatozoa with low initial motility was due to an inhibitory effect.

Casillas (1973) has established that immature bovine spermatozoa from the caput epididymidis are relatively permeable to carnitine compared with spermatozoa from the cauda. It is possible that the transient nature of the stimulation of motility by carnitine and its dose-dependence reflect the rate of penetration of carnitine into the spermatozoa. If high extracellular or slightly increased intracellular concentrations of carnitine were stimulatory and high intracellular concentrations were inhibitory, this would result in the observed initial stimulation followed by inhibition as carnitine entered the cells. Alternatively, carnitine may induce a depolarization of the plasma membrane of the spermatozoa.

The concentration of total carnitine within mature spermatozoa is extremely high (Hutson, Van Dop \& Lardy, 1977a; Brooks, 1979b) but this high concentration is not inhibitory because it represents the sum of free and acetylated carnitine (Casillas \& Erickson, 1975; Brooks, 1979c) which are balanced through the activity of carnitine acetyltransferase. However, in the present study we may have created an imbalance by adding a high concentration of carnitine on its own which would displace the equilibrium of the carnitine acetyltransferase reaction and restrict the availability of acetyl-CoA, causing a reduction in the activity of the tricarboxylic acid cycle (Brooks, 1979a). Carnitine may also reduce levels of available acetyl moieties and thereby affect intermediate metabolism and energy supply. The stored acetyl groups then act as an energy store which can be drawn on through liberation of acetyl-CoA.

Since acetylcarnitine located within spermatozoa can act as a ready source of energy (Storey \& Keyhani, 1974; Casillas \& Erickson, 1975; Hutson, Van Dop \& Lardy, 1977b), it was expected that acetyl-L-carnitine added to immature spermatozoa would stimulate their motility. The fact that acetyl-L-carnitine was not more effective than free $\mathrm{L}$-carnitine could be due to slower penetration of the spermatozoa by the former. As acetyl-D-carnitine cannot be metabolized, the observation that it stimulated sperm motility was unexpected, although not unprecedented because Fritz \& Beyer (1969) had found that it can stimulate the respiration of heart mitochondria.

Carnitine may have a number of functions within the epididymis and these functions may vary at different locations within the epididymis (Brooks, 1979a). The present results support the suggestion that carnitine may be associated with the development by spermatozoa of the 
potential for motility in the more proximal regions of the epididymis, but also imply that once this potential has developed, the high concentrations of carnitine found in more distal regions may act to maintain spermatozoa in a quiescent condition.

We thank Professor I. B. Fritz for helpful discussions throughout this study, and Dr P. K. Tubbs, University of Cambridge, and Otsuka Pharmaceutical Company, Japan, for gifts of chemicals. D.E.B. was supported by a Royal Society and Nuffield Foundation Commonwealth Bursary and by a grant from the Wellcome Trust. This investigation received financial support from the Special Programme of Research, Development and Research Training in Human Reproduction, World Health Organization.

\section{References}

Bøhmer, T. \& Johansen, L. (1978) Inhibition of sperm maturation through intervention of the carnitine system. Int. J. Androl., Suppl. 2, 565-573.

Brooks, D.E. (1979a) Carnitine in the male reproductive tract and its relation to the metabolism of the epididymis and spermatozoa. In Carnitine Biosynthesis, Metabolism and Functions, pp. 219235. Eds J. D. McGarry \& R. A. Frenkel. Academic Press, New York.

Brooks, D.E. (1979b) Biochemical environment of sperm maturation. In The Spermatozoon, pp. 23-34. Eds D. W. Fawcett \& J. M. Bedford. Urban \& Schwarzenberg, Baltimore.

Brooks, D.E. (1979c) Carnitine, acetylcarnitine and the activity of carnitine acyltransferases in seminal plasma and spermatozoa of men, rams and rats. $J$. Reprod. Fert. 56, 667-673.

Brooks, D.E., Hamilton, D.W. \& Mallek, A.H. (1973) The uptake of $\mathrm{L}$-[methy] $\left.{ }^{3} \mathrm{H}\right]$ carnitine by the rat epididymis. Biochem. Biophys. Res. Commun. 52, $1354-1360$.

Brooks, D.E., Hamilton, D.W. \& Mallek, A.H. (1974) Carnitine and glycerylphosphorylcholine in the reproductive tract of the male rat. J. Reprod. Fert. 36, $141-160$.

Casillas, E.R. (1972) The distribution of carnitine in male reproductive tissues and its effect on palmitate oxidation by spermatozoal particles Biochim. Biophys. Acta 280, 545-551.

Casillas, E.R. (1973) Accumulation of carnitine by bovine spermatozoa during maturation in the epididymis. J. biol. Chem. 248, 8227-8232.

Casillas, E.R. \& Erickson, B.J. (1975) The role of carnitine in spermatozoal metabolism: substrateinduced elevations in the acetylation state of carnitine and coenzyme $A$ in bovine and monkey spermatozoa. Biol. Reprod. 12, 275-283.

Dott, H.M. \& Foster, G.C.A. (1979) The estimation of sperm motility in semen, on a membrane slide, by measuring the area-change frequency with an image analysing computer. J. Reprod. Fert. 55, 161-166.

Fritz, I.B. \& Beyer, R.E. (1969) Apparent respiratory control in uncoupled mitochrondria. J. biol. Chem. 244, 3075-3083.

Hamilton, D.W. \& Olsen, G.E. (1976) Effects of carnitine on oxygen uptake and utilisation of [U${ }^{14} \mathrm{C}$ palmitate by ejaculated bull spermatozoa. $J$. Reprod. Fert. 46, 195-202.

Hinton, B.T. \& Setchell, B.P. (1979) Concentration and uptake of carnitine in the rat epididymis. A micropuncture study. In Carnitine Biosynthesis, Metabolism and Functions, pp. 237-250. Eds J. D. McGarry \& R. A. Frenkel. Academic Press, New York.

Hinton, B.T., Dott, H.M. \& Setchell, B.P. (1979a) Measurement of the motility of rat spermatoza collected by micropuncture from the testis and from different regions along the epididymis. J. Reprod. Fert. 55, 167-172.

Hinton, B.T., Snoswell, A.M. \& Setchell, B.P. (1979b) The concentration of carnitine in the luminal fluid of the testis and epididymis of the rat and some other mammals. J. Reprod. Fert. 56, 105-111.

Hutson, S.M., Van Dop, C. \& Lardy, H.A. (1977a) Mitochondrial metabolism of pyruvate in bovine spermatozoa. J. biol. Chem. 252, 1309-1315.

Hutson, S.M., Van Dop, C. \& Lardy, H.A. (1977b) Metabolism of pyruvate and carnitine esters in bovine epididymal sperm mitochondria. Archs Biochem. Biophys. 181, 345-352.

Johansen, L. \& Bøhmer, T. (1978) Carnitine-binding related suppressed oxygen uptake by spermatozoa. Arch. Androl. 1, 321-324.

Marquis, N.R. \& Fritz, I.B. (1975) Effects of testosterone on the distribution in the tissues of the reproductive system of the male rat. J. biol. Chem. 240, 2197-2200.

Pearson, D.J. \& Tubbs, P.K. (1967) Carnitine and derivatives in rat tissues. Biochem. J. 105, 953-963.

Storey, B.T. \& Keyhani, E. (1974) Energy metabolism of spermatozoa. II. Comparison of pyruvate and fatty acid oxidation by mitochondria of rabbit epididymal spermatozoa. Fert. Steril. 25, 857-864.

Tanphaichitr, N. (1977) In vitro stimulation of human sperm motility by acetylcarnitine. Int. J. Fert. 22, 85-91.

Turner, T.T. \& Howards, S.S. (1978) Factors involved in the initiation of sperm motility. Biol. Reprod. 18 , $571-578$. 